\title{
Ten simple rules for meaningful meetings.
}

\author{
Christopher J. Lortie ${ }^{1}$, Joseph A. Allen ${ }^{2}$, Hoby Darling ${ }^{3}$, Andy Walshe ${ }^{3}$, \\ Matt Abrahams ${ }^{4}$, and Scott Wharton ${ }^{4}$ \\ ${ }^{1}$ York University and The National Center for Ecological Analysis and Synthesis, UCSB \\ ${ }^{2}$ Department of Family and Preventive Medicine, University of Utah \\ ${ }^{3}$ Logitech, California \\ ${ }^{4}$ Department of Organizational Behavior, Graduate School of Business, Stanford
}

Corresponding author:
Christopher J. Lortie

Email address: chris@christopherlortie.info

\begin{abstract}
Most people in modern organizations do not like meetings. Frustration from the fact that there are too many meetings is a likely culprit because there at least 55 million meetings each day in the US with many millions more held around the world. The prevalence and impact of meetings suggests that they are a grand challenge to human well being. This editorial provides a contemporary set of simple rules to consider for the management of meetings and research in this specific domain. A review was used to search for concepts associated with the study of meetings through formal syntheses of evidence in the primary research literature. In total, ten rules for more meaningful meetings are identified along with a short discussion of their implications. The salient themes that emerged were a paradigm of experimental and design thinking for meetings, attention to the human dimension of meetings, technology cannot be avoided so should be carefully used, and creativity is a viable outcome from many meetings.
\end{abstract}

\section{INTRODUCTION}

Meetings are universally reviled. There are only two exceptions to this pervasive sentiment - people who call meetings and those who speak the most during meetings (Kello 2015; Lehmann-Willenbrock et al. 2018). Given the incredible frequency of meetings conservatively estimated at 55 million per day in the USA alone (Allen, Rogelberg, and Scott 2008; Keith 2015), this is a significant and grand challenge to human well being in addition to productivity, performance, and financial costs. In a recent poll of participants in 5 million meetings globally, over $40 \%$ of respondents reported that poorly organized meetings negatively impacted capacity to do work, and a similar percentage of respondents from this poll reported lack of clarity in meetings as impediments to clear actions and subsequent professional focus (Doodle 2019). This evidence supports surveys in the peer-reviewed scientific literature on these issues that reported over 50\% of respondents expressed dissatisfaction with the merit of meetings (Allen, Rogelberg, and Scott 2008; Geimer et al. 2015). A meeting in most professional and employment contexts can be defined as a planned interaction to report progress, share ideas, and to make decisions (Bouamrane and Luz 2007; Mroz et al. 2018). However, this definition is evolving to model interactions in professional contexts associated with creativity and technology (Liu et al. 2016; Pacauskas and Rajala 2017), meaningful associations with tasks (Allan 2017), and use of meetings as intervention tools in medicine to vet treatment plans and communicate with patients (Basta et al. 2017; Singer et al. 2015). Meetings can also include extemporaneous interactions in settings outside the typical work environment. The extent of research on meetings does not correspond to the extent that we use meeting as an assumed tool to complete work nor does the research fully address the extent that meetings impose costs on people and organizations (Allen, Lehmann-Willenbrock, and Rogelberg 2015). Here, we used the literature from the science of meetings that is larger-scale, synthesis driven to develop a set of simple guiding principles from the research available to date.

Contemporary scientific synthesis includes systematic reviews, meta-analyses, and the aggregation of evidence such as big data. Typically, synthesis science is differentiated from primary scientific endeavors by relatively larger-scales of inference, the compilation of evidence from varied sources, and formal, 
transparent processes of synthesis (Gómez-Aparicio and Lortie 2014; Gurevitch et al. 2018; Lajeunesse 2016; Lortie and Bonte 2016; Sutton and Higgins 2008; Whittaker 2010). When a field of primary academic study has matured to the point that there are sufficient peer-reviewed publications examining related or very similar topics through surveys or experimentation, synthesis tools become more frequent as a mechanism to summarize knowledge for that specific domain (Lortie 2014). A body of these synthesis publications can then in turn become the substrate for even larger, landscape-level insights to capture lessons and discoveries across a very large number of primary studies. The primary objective herein was to identify ten simple rules from the higher-order synthesis studies for the research both directly and indirectly associated with the science of meetings. We used the ISI Web of Science bibliometric engine to search for concepts associated with this science including meetings and review, systematic reviews, meta-analyses, productivity, creativity, and problem solving (Lortie Christopher 2019b). This process returned a total of 418 potential synthesis studies associated with meeting science (Analytics 2019). These publications were reviewed in full to identify well-established and quantitatively-supported recommendations for the improvement of meetings in some form (Lortie Christopher 2019a). A total of 36 formal synthesis publications met these two criteria, and we used this global evidence, very universally, to derive rules for better meetings in an evidence-informed capacity.

\section{RULES}

\section{Experiment with meetings.}

Meetings are an opportunity to interact. Adopt a philosophy of experimentation whereby leaders and participants alike try new ways of meeting (Ruxton and Colgrave. 2018). Use design thinking (Burdick and Willis 2011; Dorst 2011), and explore duration, frequency, venue, team size, timing, and technology (to name a few) to test whether these variables can become key factors in mediating the performance or desired outcome of meetings for your organization (Allen, Lehmann-Willenbrock, and Rogelberg 2018; Cohen et al. 2011; Murray, n.d.; Stairmand et al. 2015). There was a consistent general trend across the synthesis literature in the critical need for experimentation with meetings in the context of research and execution of meetings. Both the novelty of the experimentation and the introduction of new key practices will foster untapped gains in productivity and well being.

\section{Define meetings.}

Meaning and purpose are important determinants of professional interactions (Meyer and Maltin 2010; Meyer et al. 2002). In each and every meeting, define the purpose and function of the meeting (Forsetlund et al. 2009). Meetings that are relevant to the participants foster engagement inside and outside the meeting setting (Allen and Rogelberg 2013). Develop a vocabulary of functions for your meetings because shared social semantics promotes better synchrony (Yu, Zhou, and Nakamura 2013). These are essentially the ground rules for the process of the meeting (Allen, Rogelberg, and Scott 2008). This is not the same as setting an agenda (Stone and Brush 1996), and it is simply an opportunity to delineate the significance of the task at hand to engender motivation and commitment (Allan 2017).

\section{Use technology.}

Technology is ubiquitous in both the personal and professional setting (Wu and Shang 2019). Enable and capitalize on this technology to record, screen capture, photograph, document, and remotely include participants (Ahtinen, Andrejeff, and Vaananen 2016; Junuzovic et al. 2011; Tilahun and Levinson 2017). Technology can promote creativity and rapid processing of content (Bouamrane and Luz 2007; Pacauskas and Rajala 2017) but facilitation of e-meetings can also require unique mitigation strategies (Macaulay and Alabdulkarim 2005; Romano and Nunamaker 2001). Media richness research confirms that meetings that use higher fidelity communication tools (i.e. video conferencing instead of teleconferencing) are more efficient, effective, and engaging (Wu and Shang 2019).

\section{Avoid drift.}

Similar to sport (Liew et al. 2019), flow and momentum are important components of all productivity endeavors including meetings. Meetings should promote flow states that embrace complexity, but do not max out cognitive load of participants (Pacauskas and Rajala 2017). This includes engaging in procedural communication in meetings to promote momentum and avoid topical drift within the agreed upon framework (Lehmann-Willenbrock, Allen, and Kauffeld 2013). 


\section{Build larger teams for some meetings.}

If innovation is the primary outcome of a specific meeting, consider building larger teams including a focus on process - not product (Sarooghi, Libaers, and Burkemper 2015). Team size is likely always an important moderator of any outcome, but its influence can vary depending on the specific task (Dennis and Wixom 2002) and should be experimented with contextually (i.e. the first rule). Although some report that larger meetings are less effective (Boivie et al. 2016), the key is to build effective facilitation processes to allow for collaboration across the larger relative number of participants. Simply put, more minds can generate more creative interactions.

\section{Embrace diversity.}

Incorporating and ensuring representation from within the organization promotes commitment, retention, and satisfaction (Basta et al. 2017; Neininger et al. 2010). Build a team not an organization. An organization is a group of people that are obligated to be there whilst a team is a group of people that have come together to tackle a shared goal. Provide opportunities for all players to participate in meetings as needed (Malouff et al. 2012) and when appropriate (Allen and Rogelberg 2013).

\section{Build commitment to the meeting process.}

Leaders must support prosocial tendencies in meetings (Liu et al. 2016) and recognizing commitment to the process reduces stress (Meyer and Maltin 2010). Meetings are inherently a social function. Increased well being of employees through the process of meetings is a non-trivial benefit given the frequency and proportion of time associated with this activity in most professional contexts.

\section{Plan the design of meetings.}

Movement (Ahtinen, Andrejeff, and Vaananen 2016), configuration of space (Hill, Ferris, and Märtinson 2003), location (Ahtinen, Andrejeff, and Vaananen 2016), and breaks should be scripted a priori (Sio and Ormerod 2009). Similar to the first rule, experiment with design thinking for meetings, and test configurations socially and physically for technology and people in the places that you meet (Brown 2008; Dorst 2011).

\section{Use leadership to enhance performance (many roads to positive endpoints here).}

At a minimum, support all ideas if the goal of a meeting is creativity (Liu et al. 2016). A single leader per meeting is typically most effective (Roman et al. 2012). The meeting leader sets the tone (Schuleigh et al. 2019) and can minimize social loafing and better decision making particularly in transactional electronic interactions (Kahai, Sosik, and Avolio 2003). The importance of leadership cannot be overstated and can make or break the meeting (Mroz, Yoerger, and Allen 2018).

\section{Plan for creativity and capture these outcomes.}

Creativity is likely a fundamental component to many meetings in some respect, i.e. the production of new and useful ideas. Even if the explicit purpose of meeting is not ideation, we use ideas to solve problems and manage systems (Herrmann 2010; Hunter, Bedell, and Mumford 2009; Loehle 1990). Develop mechanisms digitally or physically in meetings to retain content and ideas (Macaulay and Alabdulkarim 2005; Sibbet 2010). Ensure agreement and communication on the mechanism before the meeting begins with all participants (Reiter-Palmon and Sands 2015). Finally, define a clear, easy way for sharing the results of the meeting.

\section{IMPLICATIONS}

There is sufficient primary research on the science of meetings to inform changes in the practice and research of interactions between people in these contexts (Mroz et al. 2018). These changes should be framed as an experimental endeavor (rule 1) in discovering the context specificity of different interactions and approaches in shaping varied outcomes from performance to satisfaction. The synthesis research is less well developed, but adopting a very broad view of meetings to include interaction research associated with meetings directly and indirectly for creativity and problem solving produced the ten simple principles described here. These emergent properties were consistent with a recent checklist of over twenty items developed from the primary literature including the general concepts of leadership, flow, goal setting, and team size as critical components (Mroz et al. 2018). Hence, there is clear evidence at many scales 
of inquiry in this research domain that meetings are primed for experimentation and improvement. The synthesis research does not close the book on the science of meetings but instead highlights opportunity and gaps for innovation. Better meetings must concurrently embrace technology and promote human well being. Technology is relatively well studied as a both a direct tool to augment meetings such as recording and video displays and indirectly as a mechanism to provide remote participation and alternative pathways to discussion such as chat functions. The social components of meetings were frequently discussed as a crucial gap in big-picture thinking for meetings. There was a paucity of synthesis studies that experimentally manipulated key factors associated with performance (i.e. most syntheses aggregated observational data). More nuanced and functional language, metrics, and specific outcome delineation was another important opportunity for the use of these rules to inform better meetings. Design of meetings both procedurally and physically was a compelling opportunity consistently identified in many studies.

Finally, we must highlight that time was a largely neglected factor in the synthesis science associated with meetings yet likely a cornerstone limitation in all professional contexts and profoundly valuable asset to manage through meetings. Meeting time, use of time, and lateness have been examined (Allen, Lehmann-Willenbrock, and Rogelberg 2018; Joseph Allen, Lehmann-Willenbrock, and Rogelberg 2018; Lehmann-Willenbrock and Allen 2018) but not compiled in a formal synthesis to date. Flow and pacing were proposed as a meaningful principle to consider here, but from the primary literature, duration was identified as a critical factor in meetings (Leach et al. 2009) and proposed in the checklist to schedule lengths that fit and consider shorter meetings (Mroz et al. 2018). Rules are at best heuristics, and these rules in particular should be viewed as a synthesis and prescription of what is possible not what is definitely known. Clearly based on the satisfaction statistics reported for meetings, the sky is the limit, and better meetings through experimentation with these rules is a path forward to more positive interactions and performance.

\section{REFERENCES}

Ahtinen, A., E. Andrejeff, and K. Vaananen. 2016. "Brainwolk: A Mobile Technology Mediated Walking Meeting Concept for Wellbeing and Creativity at Work." Journal Article. Mobile and Ubiquitous Multimedia DOI:10.1145/3012709.3016062.

Allan, Blake A. 2017. “Task Significance and Meaningful Work: A Longitudinal Study.” Journal Article. Journal of Vocational Behavior 102: 174-82. https://doi.org/https://doi .org/ $10.1016 / j . j v b .2017 .07 .011$.

Allen, J.A., Steven G. Rogelberg, and J. Scott. 2008. "Meaningful Meetings: Improve Your Organization's Effectiveness One Meeting at a Time." Journal Article. Quality Progress 41: 48-53.

Allen, Joseph A., Nale Lehmann-Willenbrock, and Steven G. Rogelberg, eds. 2015. "The Cambridge Handbook of Meeting Science.” Book Section. In The Cambridge Handbook of Meeting Science, i-ii. Cambridge Handbooks in Psychology. Cambridge: Cambridge University Press. https://doi.org/DOI: undefined

2018. "Let's Get This Meeting Started: Meeting Lateness and Actual Meeting Outcomes."

Journal Article. Journal of Organizational Behavior 39 (8): 1008-21. https://doi.org/10. 1002 / job.2276.

Allen, Joseph A., and Steven G. Rogelberg. 2013. "Manager-Led Group Meetings: A Context for Promoting Employee Engagement.” Journal Article. Group \& Organization Management 38 (5): 543-69. https://doi.org/10.1177/1059601113503040

Allen, Joseph, Nale Lehmann-Willenbrock, and Steven Rogelberg. 2018. "Let's Get This Meeting Started: Meeting Lateness and Actual Meeting Outcomes.” Journal Article. Journal of Organizational Behavior. https://doi.org/10.1002/job.2276.

Analytics, Clarivate. 2019. “Core Collection.” Journal Article. Web of Science August.

Basta, Y.L., S. Bolle, P. Fockens, and K. Tytgat. 2017. "The Value of Multidisciplinary Team Meetings for Patients with Gastrointestinal Malignancies: A Systematic Review.” Journal Article. Annals of Surgical Oncology 24. https: / / doi .org/10.1245/s10434-017-5833-3.

Boivie, Steven, Michael K. Bednar, Ruth V. Aguilera, and Joel L. Andrus. 2016. "Are Boards Designed to Fail? The Implausibility of Effective Board Monitoring." Journal Article. Academy of Management Annals 10 (1): 319-407. https: / / doi .org/10.5465/19416520.2016.1120957.

Bouamrane, Matt- M., and Saturnino Luz. 2007. "Meeting Browsing." Journal Article. Multimedia Systems 12 (4): 439-57. https://doi.org/10.1007/s00530-006-0066-5. 
Brown, Tim. 2008. "Design Thinking." Journal Article. Harvard Business Review 86 (6): 84-92. http://search.ebscohost. com/login.aspx?direct=true\&db=bth\&AN= $32108052 \&$ site=ehost-live.

Burdick, Anne, and Holly Willis. 2011. "Digital Learning, Digital Scholarship and Design Thinking." Journal Article. Design Studies 32 (6): 546-56. https://doi.org/https://doi.org/10. $1016 / j$. destud.2011.07.005.

Cohen, Melissa A., Steven G. Rogelberg, Joseph A. Allen, and Alexandra Luong. 2011. "Meeting Design Characteristics and Attendee Perceptions of Staff/Team Meeting Quality.” Journal Article. Group Dynamics: Theory, Research, and Practice 15 (1): 90-104. https: //doi .org/10.1037/ a 0021549 .

Dennis, Alan R., and Barbara H. Wixom. 2002. "Investigating the Moderators of the Group Support Systems Use with Meta-Analysis.” Journal Article. Journal of Management Information Systems 18 (3): 235-57. https://doi.org/10.1080/07421222.2002.11045696.

Doodle. 2019. “The State of Meetings 2019.” Journal Article. Doodle Blog.

Dorst, Kees. 2011. "The Core of 'Design Thinking' and Its Application.” Journal Article. Design Studies 32 (6): 521-32. https://doi.org/https://doi.org/10.1016/j.destud.2011. 07.006

Forsetlund, Louise, Arild Bjørndal, Arash Rashidian, Gro Jamtvedt, Mary Ann O'Brien, Fredric Wolf, Dave Davis, Jan Odgaard-Jensen, and Andrew Oxman. 2009. "Continuing Education Meetings and Workshops: Effects on Professional Practice and Health Care Outcomes." Journal Article. Cochrane Database of Systematic Reviews (Online) 2: CD003030. https://doi.org/10.1002/14651858. CD003030 pub2.

Geimer, Jennifer L., Desmond J. Leach, Justin A. DeSimone, Steven G. Rogelberg, and Peter B. Warr. 2015. "Meetings at Work: Perceived Effectiveness and Recommended Improvements." Journal Article. Journal of Business Research 68 (9): 2015-26. https : / / doi .org/https: //doi .org/ $10.1016 / j \cdot j b u s r e s .2015 .02 .015$.

Gómez-Aparicio, Lorena, and Christopher J. Lortie. 2014. "Advancing Plant Ecology Through Meta-Analyses." Journal Article. Journal of Ecology 102 (4): 823-27. https://doi .org/10. $1111 / 1365-2745.12264$

Gurevitch, Jessica, Julia Koricheva, Shinichi Nakagawa, and Gavin Stewart. 2018. "Meta-Analysis and the Science of Research Synthesis." Journal Article. Nature 555: 175. https: / / doi . org/10. 1038 /nature25753.

Herrmann, Thomas. 2010. "Support of Collaborative Creativity for Co-Located Meetings." Book Section. In From Cscw to Web 2.0: European Developments in Collaborative Design: Selected Papers from Coop08, edited by David Randall and Pascal Salembier, 65-95. London: Springer London. https: //doi.org/10.1007/978-1-84882-965-7_4.

Hill, E. Jeffrey, Maria Ferris, and Vjollca Märtinson. 2003. "Does It Matter Where You Work? A Comparison of How Three Work Venues (Traditional Office, Virtual Office, and Home Office) Influence Aspects of Work and Personal/Family Life.” Journal Article. Journal of Vocational Behavior 63 (2): 220-41. https://doi.org/https://doi.org/10.1016/S0001-8791 (03)00042-3.

Hunter, S.T., K.E. Bedell, and M.D. Mumford. 2009. "Climate for Creativity: A Quantitative Review." Journal Article. Creativity Research Journal 19: 69-90.

Junuzovic, Sasa, Kori Inkpen, Rajesh Hegde, Zhengyou Zhang, John Tang, and Christopher Brooks. 2011. What Did I Miss? In-Meeting Review Using Multimodal Accelerated Instant Replay (Air) Conferencing. Book. https://doi.org/10.1145/1978942.1979014.

Kahai, Surinder S., John J. Sosik, and Bruce J. Avolio. 2003. "Effects of Leadership Style, Anonymity, and Rewards on Creativity-Relevant Processes and Outcomes in an Electronic Meeting System Context." Journal Article. The Leadership Quarterly 14 (4): 499-524. https://doi .org/https://doi. org/10.1016/S1048-9843(03)00049-3.

Keith, E. 2015. "55 Million: A Fresh Look at the Number, Effectiveness, and Cost of Meetings in Us." Journal Article. Lucidmeetings.com https://blog.lucidmeetings.com/blog/fresh-look-number-effectivenesscost-meetings-in-us.

Kello, J.E. 2015. “The Science and Practice of Workplace Meetings.” Book Section. In The Cambridge Handbook of Meeting Science, edited by \& S. G. Rogelberg J. A. Allen N. Lehmann-Willenbrock, 709-34. New York, NY, USA: Cambridge University Press. 
Lajeunesse, Marc J. 2016. "Facilitating Systematic Reviews, Data Extraction and Meta-Analysis with the Metagear Package for R.” Journal Article. Methods in Ecology and Evolution 7 (3): 323-30. https://doi.org/10.1111/2041-210X.12472.

Leach, Desmond J., Steven G. Rogelberg, Peter B. Warr, and Jennifer L. Burnfield. 2009. "Perceived Meeting Effectiveness: The Role of Design Characteristics." Journal Article. Journal of Business and Psychology 24 (1): 65-76. https://doi.org/10.1007/s10869-009-9092-6.

Lehmann-Willenbrock, Nale, and Joseph A. Allen. 2018. "Modeling Temporal Interaction Dynamics in Organizational Settings." Journal Article. Journal of Business and Psychology 33 (3): 325-44. https://doi.org/10.1007/s10869-017-9506-9.

Lehmann-Willenbrock, Nale, Joseph A. Allen, and Simone Kauffeld. 2013. "A Sequential Analysis of Procedural Meeting Communication: How Teams Facilitate Their Meetings." Journal Article. Journal of Applied Communication Research 41 (4): 365-88. https://doi.org/10.1080/00909882. 2013.844847

Lehmann-Willenbrock, Nale, Steven G. Rogelberg, Joseph A. Allen, and John E. Kello. 2018. "The Critical Importance of Meetings to Leader and Organizational Success: Evidence-Based Insights and Implications for Key Stakeholders." Journal Article. Organizational Dynamics 47 (1): 32-36. https://doi.org/https://doi.org/10.1016/j.orgdyn.2017.07.005.

Liew, Guo Chen, Garry Kuan, Ngien Siong Chin, and Hairul Anuar Hashim. 2019. "Mental Toughness in Sport." Journal Article. German Journal of Exercise and Sport Research. https: //doi.org/10.1007/s12662-019-00603-3.

Liu, Dong, Kaifeng Jiang, Christina E. Shalley, Sejin Keem, and Jing Zhou. 2016. "Motivational Mechanisms of Employee Creativity: A Meta-Analytic Examination and Theoretical Extension of the Creativity Literature.” Journal Article. Organizational Behavior and Human Decision Processes 137: 236-63. https://doi.org/https://doi.org/10.1016/j.obhdp.2016.08.001

Loehle, C. 1990. "A Guide to Increased Creativity in Research - Inspiration or Perspiration?" Journal Article. BioScience 40 (2): 123-29.

Lortie, Christopher J., and Dries Bonte. 2016. "Zen and the Art of Ecological Synthesis." Journal Article. Oikos 125 (3): 285-87. https://doi.org/10.1111/oik.03161

Lortie, C. J. 2014. "Formalized Synthesis Opportunities for Ecology: Systematic Reviews and Meta-Analyses." Journal Article. Oikos 123: 897-902.

Lortie Christopher, J. 2019a. "PRISMA for the Synthesis Science of Meetings." Journal Article. Figshare. https://doi.org/10.6084/m9.figshare.10277804.v2.

- 2019b. "The Synthesis Science of Meetings." Journal Article. Figshare Dataset. https: //doi.org/10.6084/m9.figshare.10032122.v1.

Macaulay, Linda, and A. Alabdulkarim. 2005. Facilitation of E-Meetings: State-of-the-Art Review. Book. https://doi.org/10.1109/EEE.2005.73.

Malouff, John, Alexsandra Calic, Catherine McGrory, and Rebecca Murrell. 2012. "Evidence for a Needs-Based Model of Organizational-Meeting Leadership." Journal Article. Current Psychology 31. https://doi.org/10.1007/s12144-012-9129-2.

Meyer, John P., and Elyse R. Maltin. 2010. "Employee Commitment and Well-Being: A Critical Review, Theoretical Framework and Research Agenda." Journal Article. Journal of Vocational Behavior 77 (2): 323-37. https://doi.org/https://doi.org/10.1016/j.jvb.2010.04.007

Meyer, John P., David J. Stanley, Lynne Herscovitch, and Laryssa Topolnytsky. 2002. "Affective, Continuance, and Normative Commitment to the Organization: A Meta-Analysis of Antecedents, Correlates, and Consequences." Journal Article. Journal of Vocational Behavior 61 (1): 20-52. https://doi.org/https://doi.org/10.1006/jvbe.2001.1842.

Mroz, Joseph E., Joseph A. Allen, Dana C. Verhoeven, and Marissa L. Shuffler. 2018. "Do We Really Need Another Meeting? The Science of Workplace Meetings." Journal Article. Current Directions in Psychological Science 27 (6): 484-91. https://doi.org/10.1177/0963721418776307.

Mroz, Joseph E., Michael Yoerger, and Joseph A. Allen. 2018. "Leadership in Workplace Meetings: The Intersection of Leadership Styles and Follower Gender." Journal Article. Journal of Leadership \& Organizational Studies 25 (3): 309-22. https://doi.org/10.1177/1548051817750542.

Murray, Gabriel. n.d. "Analyzing Productivity Shifts in Meetings." Conference Proceedings. In Advances in Artificial Intelligence, edited by Denilson Barbosa and Evangelos Milios, 141-54. Springer International Publishing. 
Neininger, Alexandra, Nale Lehmann-Willenbrock, Simone Kauffeld, and Angela Henschel. 2010. "Effects of Team and Organizational Commitment - a Longitudinal Study." Journal Article. Journal of Vocational Behavior 76 (3): 567-79. https://doi.org/https://doi.org/10.1016/j. jvb.2010.01.009.

Pacauskas, D., and R. Rajala. 2017. "Information System Users' Creativity." Journal Article. Information Technology \& People 30: 81-116.

Reiter-Palmon, Roni, and S. Sands. 2015. "Creativity and Meetings: Do Team Meetings Facilitate or Hinder Creative Team Performance?" Book Section. In, 585-614. https://doi.org/10.1017/ CB09781107589735.025.

Roman, Flaviu, Himanshu Verma, Patrick Jermann, and Pierre Dillenbourg. 2012. Group Dynamics Findings from Coordination in Problem Solving and Decision Making Meetings. Book. https:// doi. org/10.1145/2389176.2389232.

Romano, Nicholas, and Jay Nunamaker. 2001. Meeting Analysis: Findings from Research and Practice. Book.

Ruxton, G.D., and N. Colgrave. 2018. Experimental Design for the Life Sciences. Book. Fourth. Oxford, UK: Oxford University Press.

Sarooghi, Hessamoddin, Dirk Libaers, and Andrew Burkemper. 2015. "Examining the Relationship Between Creativity and Innovation: A Meta-Analysis of Organizational, Cultural, and Environmental Factors." Journal Article. Journal of Business Venturing 30 (5): 714-31. https://doi . org/https: //doi.org/10.1016/j.jbusvent.2014.12.003.

Schuleigh, V.E., J.M. Malouff, Nicola S. Schutte, and N.M. Loi. 2019. "Enhancing Meetings: The Impact of Leader Behavior." Journal Article. Journal of Leadership and Education 18: 41-52.

Sibbet, D. 2010. Visual Meetings: How Graphics, Sticky Notes and Idea Mapping Can Transform Group Productivity. Book. New Jersey: Wiley \& Sons.

Singer, A.E., T. Ash, C. Ochotorena, K.A. Lorenz, K. Chong, S.T. Shreve, and S.C. Ahluawalia. 2015. "A Systematic Review of Family Meeting Tools in Palliative and Intensive Care Settings." Journal Article. American Journal of Hospice \& Palliatice Medicine 33: 797-806.

Sio, Ut Na, and Thomas C. Ormerod. 2009. "Does Incubation Enhance Problem Solving? A MetaAnalytic Review.” Journal Article. Psychological Bulletin 135 (1): 94-120. https://doi .org/10. $1037 / a 0014212$

Stairmand, J., L. Signal, D. Sarfati, C. Jackson, L. Batten, M. Holdaway, and C. Cunningham. 2015. "Consideration of Comorbidity in Treatment Decision Making in Multidisciplinary Cancer Team Meetings: A Systematic Review." Journal Article. Annals of Oncology 26 (7): 1325-32. https: //doi.org/10.1093/annonc/mdv025.

Stone, Melissa Middleton, and Candida Greer Brush. 1996. "PLANNING in Ambiguous Contexts: THE Dilemma of Meeting Needs for Commitment and Demands for Legitimacy." Journal Article. Strategic Management Journal 17 (8): 633-52. https://doi.org/10.1002/(SICI)10970266(199610)17:8<633::AID-SMJ837>3.0.CO;2-6.

Sutton, A. J., and J. P. I. Higgins. 2008. "Recent Developments in Meta-Analysis." Journal Article. Stat Med 27. https://doi.org/10.1002/sim.2934

Tilahun, Nebiyou, and David Levinson. 2017. "Contacts and Meetings: Location, Duration and Distance Traveled." Journal Article. Travel Behaviour and Society 6: 64-74. https://doi.org/ https://doi.org/10.1016/j.tbs.2016.06.002.

Whittaker, R. J. 2010. "Meta-Analyses and Mega-Mistakes: Calling Time on Meta-Analysis of the Species Richness-Productivity Relationship.” Journal Article. Ecology 91. https://doi.org/10. $1890 / 08-0968.1$

Wu, W., and D. Shang. 2019. "Employee Usage Intention of Ubiquitous Learning Technology: An Integrative View of User Perception Regarding Interactivity, Software, and Hardware." Journal Article. IEEE Access 7: 34170-8. https://doi.org/10.1109/ACCESS.2019.2893311.

Yu, Z., X. Zhou, and Y. Nakamura. 2013. "Extracting Social Semantics from Multimodal Meeting Content." Journal Article. IEEE Pervasive Computing 12 (2): 68-75. https://doi .org/10.1109/ MPRV.2012.55. 